\title{
An energy-based method for lifetime assessment on high strength steel welded joints under different pre-strain levels
}

\author{
Chengji Mi ${ }^{1}$, Zhonglin Huang ${ }^{1}$, Haibo Wang ${ }^{1}$, Dong Zhang ${ }^{1}$, Tao Xiong ${ }^{1}$, Haigen Jian ${ }^{1}$, \\ and Chengji $\mathrm{Mi}^{1}$
}

${ }^{1}$ Hunan University of Technology

February 10, 2022

\begin{abstract}
The pre-loading on the engineering materials or structures may produce pre-strain, especially plastic strain, which would change the fatigue failure mechanism during their service time. In this paper, an energy-based method for fatigue life prediction on high strength steel welded joints under different pre-strain levels was presented. Three kinds of tensile pre-straining were conducted on the specimens, and the cyclic stress and strain responses with pre-loading were compared with the ones without pre-loading at the same strain level. The experimental work showed that the plastic strain energy density of pre-strained welded joints was enlarged, while the elastic strain energy density of pre-strained welded joints was reduced. Then, based on the strain energy density method, a fatigue life estimation model of the high strength steel welded joints in consideration of the pre-straining was proposed. The predicted results agreed well with the test data.
\end{abstract}

\section{Hosted file}

manuscript2.8.doc available at https://authorea.com/users/459775/articles/555924-anenergy-based-method-for-lifetime-assessment-on-high-strength-steel-welded-joints-underdifferent-pre-strain-levels 